\title{
Requirement Model of Conference Management System: A Mobile App for Creating and Managing Conference Paper
}

$\underline{\text { https://doi.org/10.3991/ijim.v13i11.11280 }}$

\author{
Azham Hussain ${ }^{\bowtie)}$, Chow Chun Leong, Nurnasran Puteh \\ Universiti Utara Malaysia, Kedah, Malaysia \\ azhamuumegmail.com \\ Zarul Fitri Zaaba \\ Universiti Sains Malaysia, Pulau Pinang, Malaysia
}

\begin{abstract}
Technology has changed the way we work. These have increased the productivity in the workplace. The purpose of having a conference paper app is to aid researcher to improve the effectiveness and efficiency of management of conference paper. Without a proper management of these substances, people might suffer from the inconvenience by using a desktop system to complete certain tasks and monitor them efficiently. However, based on investigating the existing applications, a few shortcomings have been identified. Certain shortcoming leads us to develop a new mobile application to fix the identified shortcomings. Some others include complex navigation of user interfaces, this cause a poor user experience for users. Hence, this project proposes a development of a mobile application that is called CPMA, which serve as a better alternative tool to allow users managing and monitoring information related to conference paper in a more efficient way. This app specifically developed for researchers in higher learning institutions who are needed to proceed with conference paper. Software development methodology named prototyping will be adopted, which consisted of phases such as planning, repeated phases (analysis, design, implementation and system prototype), implementation and final system. The essential significance of this project is to provide a platform for researcher to manage and monitor conference paper in a savvy manner. By the time of completing this project, users are expected to access this application without any costs and increase the efficiency and effectiveness of managing conference paper. To ensure the security is presented in a tabular form for each online marketplace.
\end{abstract}

Keywords - Conference Paper, Knowledge Management, Mobile Application.

\section{Introduction}

Smartphones and tablets have become one of the daily necessities among people. Almost every person has a smartphone or tablet by their side whenever they go 
$[11,12]$. This has become a habit for most people to rely on their gadget for planning their daily basis. The mobile phone has become such an important aspect of people's everyday life [10]. Through using a mobile device, people's productivity in various aspect obviously increased with convenient from a mobile device. In aspect Ecommence, mobile phone user can view product, select product and order for product in online. Sometimes, mobile application Mobile Wallet is used in restaurant or market for making payment. People can do business work using the mobile application. Mobile online banking and e Ticketing is another feature of mobile application [7]. Besides that, mobile device also helping users to save time and effort in communication. Conference papers usually very short (number of pages) and include a preliminary result of a research project [3]. Paper-based management system have been used for managing conference paper earlier. However, paper-based conference paper management system is not really convenient and environmentally friendly these days [9]. Besides, a researcher has also faced the risk of physical damage. In this case, technology has played an important role. By introducing a conference paper mobile application that is available to download from either Android platform, which is really convenient, portable and flexible. Since every person owns a mobile phone and know how they works, so develop a conference paper management system in mobile-based is a wise choice. Thus, the researcher can easily perform any functions like to submit conference paper and delete the submitted conference paper to manage conference paper in mobile phone. Bringing them quick manipulation of their conference paper in just swipes and clicks.

\section{Background}

After exploring and reviewing few existing applications installed, a few shortcomings have been identified. First and foremost, the problem arises from the inconvenience which manage conference article in desktop. By using mobile to manage conference paper, it will improve the mobility that means user can easily access the conference paper data through internet from everywhere. The desktop user still needs an office environment and sitting at a desk to access the conference paper data [1]. This inconvenience makes the users to take times and effort to prepare an office environment. Furthermore, complex navigation of user interface leads users hard to understand the flow of that application and much longer time to access what they want [2]. Besides that, the desktop will take longer time than a mobile phone to open the conference paper submission system, because the desktop needs to spend booting time in average 5 second to 3 minutes. At the end of this project, an application will be developed with above constrains eliminated. An interactive and user-friendly user interface will be given priority, aiding users to access what they want in a short period of time. 


\subsection{Project objective}

This project aims to propose a mobile application named Conference Paper Mobile Application (CPMA) to help user managing/monitoring the conference paper in a more efficient way. The objectives of this study are to gather requirements for CPMA, to analyze and design CPMA based on the requirements gathered, to implement CPMA with user-friendly features and evaluate CPMA.

\subsection{Literature review}

Online submission system: With the spread of the Internet, many kinds of system used to manage various matters, and provide different service in online. Especially, online submission system has helped the user to easily manage the entire submitted documents in online. Mark. Ware stated that online submission system is allowed the submission of articles and the subsequent peer-review processes to be managed within an electronic environment with a (customizable) degree of automation, and communication with all authors, referees and editors taking place electronically [8]. However, the abuse of online submission, fake peer reviews and editor-created accounts are gradually deteriorating.

In Jaime A. Teixeira da Silva's research study, there has been an increase in the number of cases in which Online Submission System has been abused, mostly by the authorship, either through the creation of fake identities or the use of false e-mail accounts. These issues raised by the imperfect of the current Online Submission System, the system still have security issues and may not be able to detect false information, except through post-submission verification [6].

\subsection{Mobile application}

Mobile applications (also known as mobile apps) are software programs developed for mobile devices such as smartphones and tablets. Md. Rashedul Islam stated that through the mobile application, user can easily to contact friends, browse internet, file content management, document creating and handling, and entertainment. From everywhere user can use the mobile application [7].

\section{Methodology of Study}

Software development methodology that is utilized in this project is prototyping model. It is a methodology which a prototype is built, tested and then reworked as necessary until an acceptable prototype is finally achieved from which the complete system or product can now be developed. Prototyping is used when aspects of functionality need to be demonstrated. It can be viewed a 'process' which is either a well-defined phase within the software development life cycle or is an 'approach' that influences the whole of it [5]. 
Each phase will cover different activities, methods and expectation. Floyd describes the prototyping process as consisting of functional selection, construction, evaluation and further use. Those functions that are to be prototyped are selected and a prototype is constructed. Diagram 1 shows the process of prototyping model.

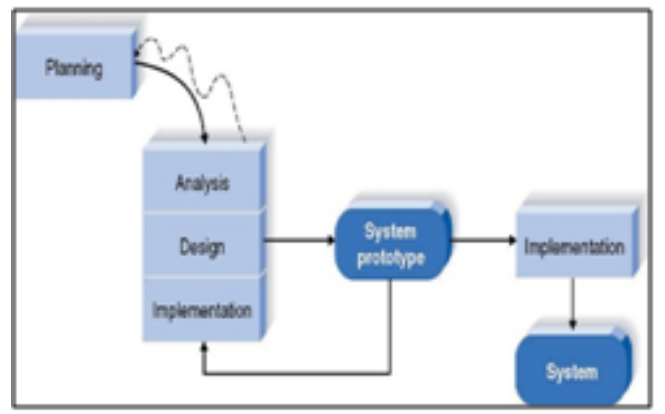

Fig. 1. Prototyping Model

The process of prototyping involved in this project included planning, repeated phases (analysis, design, implementation and system prototype), implementation and final system.

\subsection{Planning}

Planning phase helps to identify issues and problem of existing similar applications as well as to identify potential solutions to provide basic concepts and idea to the proposed project. This will be done through conducting a content analysis towards existing similar applications and reviews some online materials as to obtain some facts and terminology of knowledge required for this project. A project proposal is produced during this phase.

\subsection{Analysis}

An analysis phase helps the gathered requirements to be documented, tracked and analyzed which will set the project lifecycle and direction to work. Then, analyze the requirements gathered to clarify the needs of this project. The required requirements will be gathered through a detailed content analysis, among the similar existing applications, and conducting a simple, unstructured interview, particularly to gauge some additional inputs to design the proposed mobile app. Then, these requirements will be analyzed utilizing an Object-Oriented Analysis (OOA) approach using UML. A list of requirements will be the main outcome of this phase. 


\subsection{Design}

Design phase helps to transform the analyzed requirements into design deliverables (case diagram, use case specification, activity diagram, sequence diagram and class diagram) in order to execute the prototype through a good interface design. Hence, a design composed of flows and solutions is sketched. This can be done through the help of Object-Oriented Design (OOD) approach applying UML and hand-sketched user interfaces. UML deliverables and sketches of interfaces will be produced in this phase.

\subsection{Implementation}

Implementation phase helps to transform designs into a low fidelity prototype using an integrated development environment (IDE) named Android Studio. Hence, design sketched will be transformed into a prototype that is able to run. Low fidelity prototype of CPMA is expected to be produced in this phase.

\subsection{System Prototype}

System prototype phase helps to produce high fidelity prototype which will then proceed to testing and evaluation of prototype [5]. The prototype application will go through an application testing (unit and functional testing) and users' evaluation (usability and user satisfaction) to ensure the development app works as expected and satisfies users' needs. This process is expected to produce high fidelity prototype of CPMA testing scripts and evaluation measures.

\section{Design and Development of CPMA}

This section describes the design and development of a mobile app for creating and managing conference paper following the phases of prototyping model. The section is divided into two sub-sections; the requirements of the mobile app for creating and managing CPMA and the prototype development of CPMA; a mobile app developed to demonstrate the requirements gathered.

A requirement gathering process was carried out using a method which is analyzing documents and apps from the Internet and Play Store that are related to conference paper. During the requirements gathering process, documents were searched using Google search engine by providing keywords primarily "conference paper", "article" and "mobile based conference paper management system". The documents were analyzed to elicit the requirements for a mobile app that can create and manage conference paper. Table 2 lists six significant requirements (and their priority) produced from the requirements gathering process. The requirements include login, manage submissions, manage files, view status, modify the submitted conference paper's status, and view conference paper. 
Table 1. List of requirements

\begin{tabular}{|c|l|c|}
\hline No & \multicolumn{1}{|c|}{ Requirement Description } & Priority \\
\hline 1 & Login & \\
\hline 1.1 & Admin can login as admin role with id and password & $\mathrm{M}$ \\
\hline 1.2 & Author can login as Author role with id and password & $\mathrm{M}$ \\
\hline 1.3 & Author can register as Author role using this application & $\mathrm{M}$ \\
\hline 2 & Manage submission & $\mathrm{M}$ \\
\hline 2.1 & Author can make a submission through this application & $\mathrm{O}$ \\
\hline 2.2 & Author can edit the submitted conference paper's information & $\mathrm{M}$ \\
\hline 2.3 & Author can withdraw submission through this application & \\
\hline 3 & Manage file & $\mathrm{M}$ \\
\hline 3.1 & Author can view files in this application & $\mathrm{M}$ \\
\hline 3.2 & Author can replace the submitted conference paper with new conference paper & \\
\hline 4 & View status & $\mathrm{M}$ \\
\hline 4.1 & $\begin{array}{l}\text { Author can view to know whether the submitted conference paper is accepted or } \\
\text { rejected }\end{array}$ & \\
\hline 5 & Modify the submitted conference paper's status & $\mathrm{M}$ \\
\hline 5.1 & Admin can modify conference paper's status, which submitted by the author & $\mathrm{M}$ \\
\hline 5.2 & $\begin{array}{l}\text { After modifying the status, the application will automatically send email to the } \\
\text { author for informing the result of verification }\end{array}$ & \\
\hline 6 & View conference paper & $\mathrm{M}$ \\
\hline 6.1 & Admin can view the conference paper which submitted by authors in this application & \\
\hline
\end{tabular}

The use case diagram is detailed out to show the dynamic behavior of the app in table 1. Hence, the operations involved in using the mobile app for creating and managing conference papers are illustrated in an activity diagram of figure 2 . 


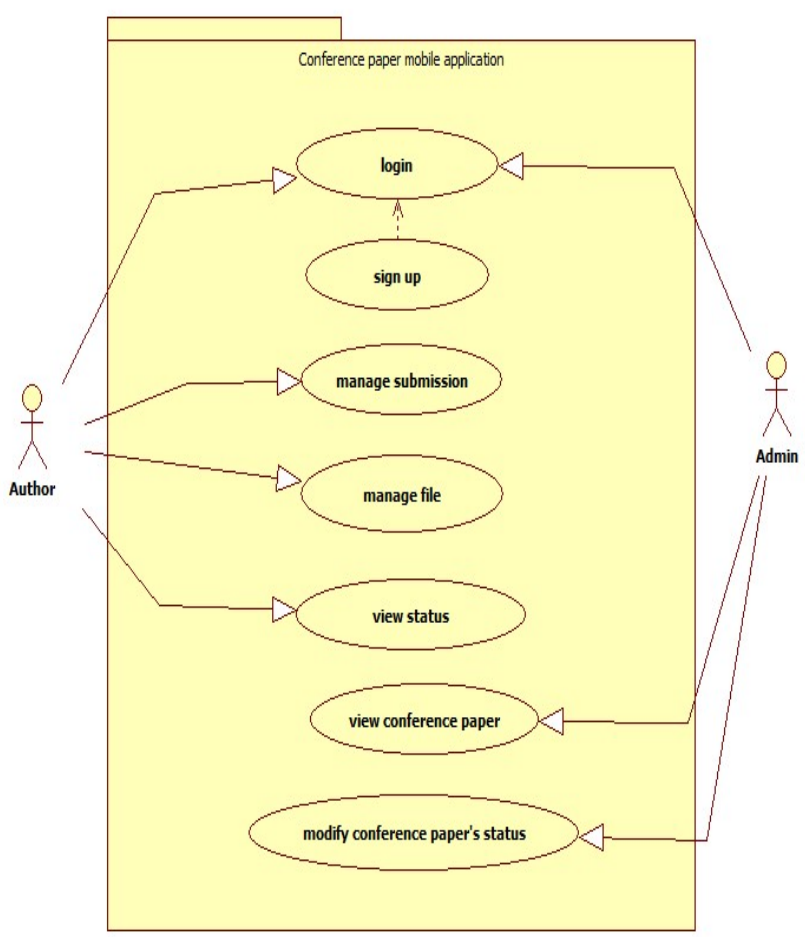

Fig. 2. Use case diagram of the CPMA

Diagram 2 shows the use case of the CPMA. The main use case of CPMA is "Manage submission" as it mainly focuses on helping author manage conference paper easily. Login use case allows users to register and login to use all the functions in this application. Manage file allows users to manage their conference paper in this application. Moreover, view status allows users to view the submitted conference paper's status easily in this application. Admin can allow to modify the submitted conference paper's status and after verification. Lastly, Admin also can view the conference paper which submitted by authors in this application.

The structural components of a mobile app for creating and managing conference paper are represented on a class diagram as illustrated in figure 3 . The class diagram in diagram 4 shows the attributes and operations of the app. The interactions between the classes are illustrated clearly in the diagram. 


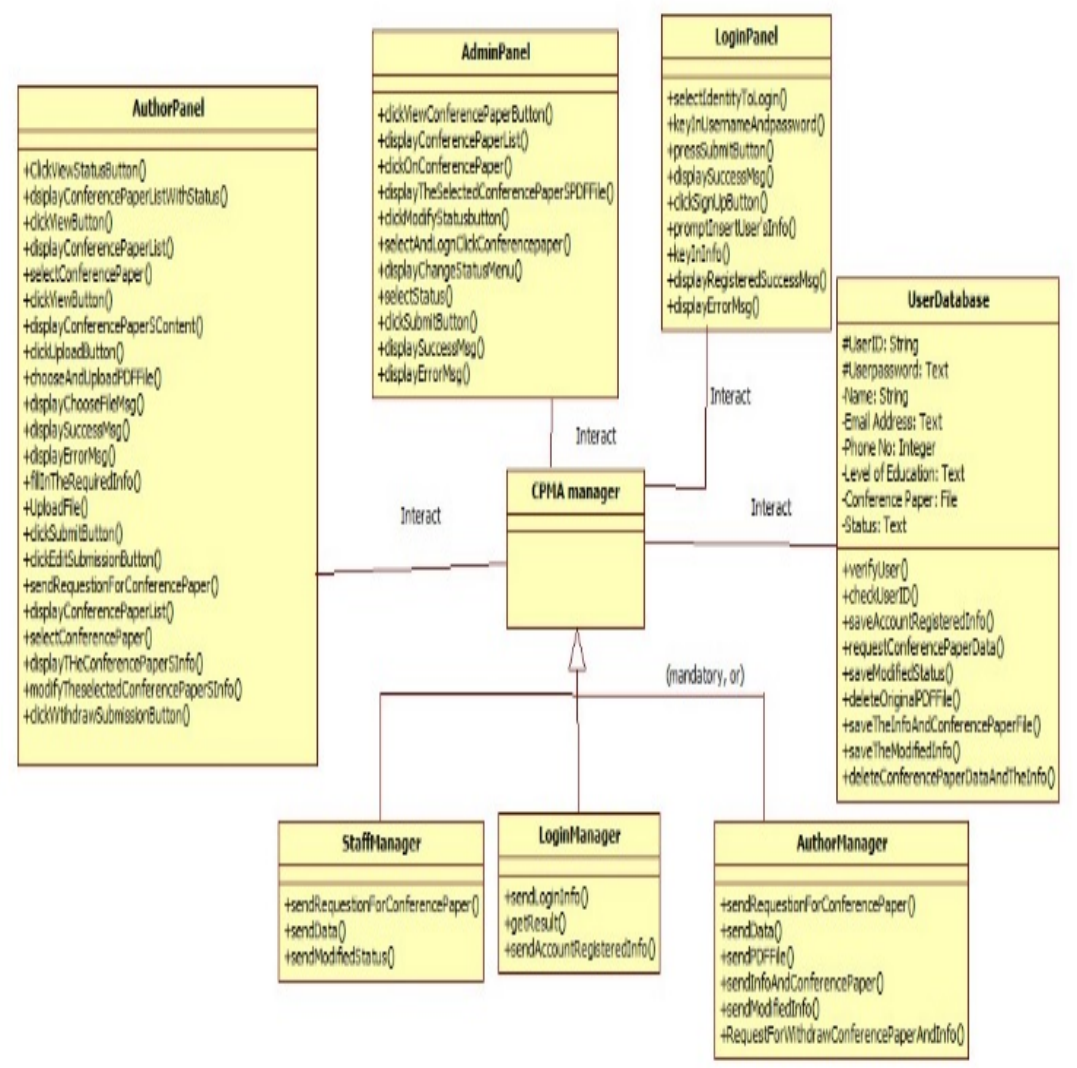

Fig. 3. Class diagram of CPMA

\subsection{The Application}

A prototype of a mobile app for creating and managing grocery list named CPMA was developed. It represents the requirements explained in the previous subsection. Software prototyping is a standard way of demonstrating the software requirements so that further comments and suggestions could be obtained from the users based on their experience in interacting with the prototype. Android Studio was used as the main integrated development environment (IDE) tool. Further, the Firebase development platform was used to facilitate crucial functions like user authentication, and database for data storage [4]. Screenshots in Figures 4 show the selected interfaces of the main use case which is managed to do list during prototype development. 


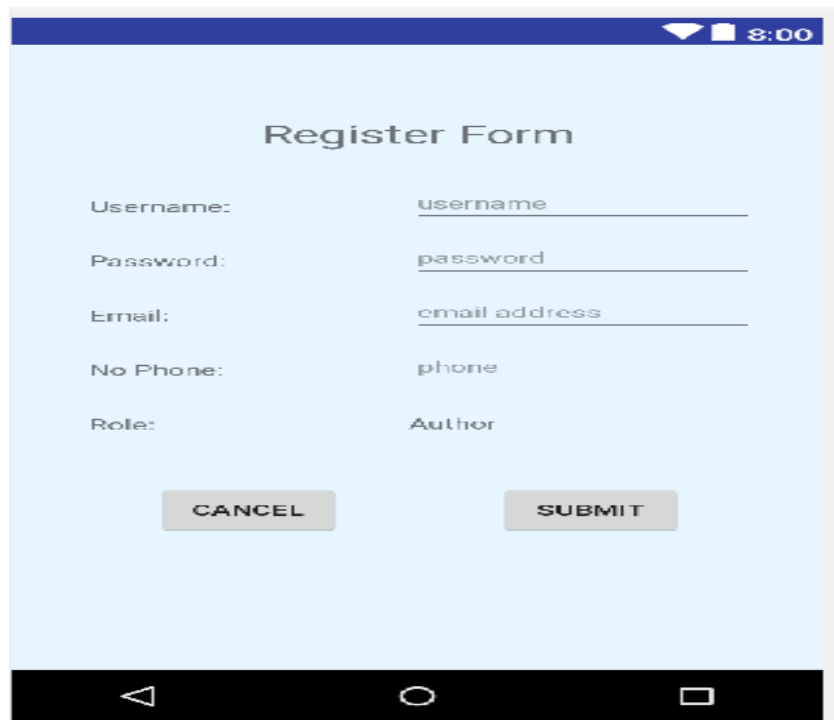

Fig. 4. Register Form

Prototype is evaluated until the prototype is further used for outlining specification or as a part of the new system. The system is a fully functional and working application after iteration of application development and enhancement of the prototype. Naumann and Jenkins characterize prototyping as a four step, iterative procedure involving users and developers:

- Users' requirements are identified

- A working prototype is developed

- he working prototype is then implemented and used

- The prototype system is revised and enhanced

This process undergoes several iterations and steps three and four are repeated until the user accepts the system. Only then final system is produced. Figure 5 shows manage conference paper in CPMA. 


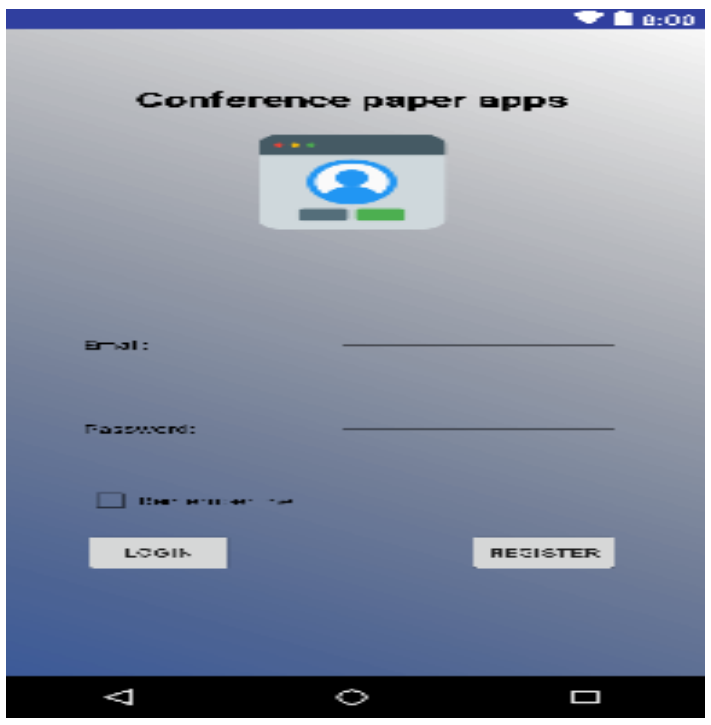

Fig. 5. Login Interface

\subsection{Evaluation of CPMA}

A usability evaluation was conducted on 15 respondents and this has two categories which is an admin role group consist of 5 people and user (lecturer) role group consist of 10 persons. The respondents were picked by the developer which all of them are lecturers and close friends. However, participation of the evaluation is on a voluntary basis. The instruments used for the evaluation were the CPMA application and a post-task questionnaire. The questionnaire is created and distributed through google form and link to download CPMA is etched within. The post-task questionnaire was adapted from which consists of 8 items in two sections. Section A consists about demography and the background of the respondents. Section B consists of various aspects to measure performance of the application. Section B is evaluated by linear scale ranging from 1 to 7 corresponding from strongly disagrees to strongly agree.

\subsection{Finding of evaluation}

Section A: Demography and background (User: Lecturer): Analysis of the user group questionnaire about the demographic information revealed that the total number of admin group respondents is ten respondents. All of them are lecturer. There, $70 \%$ respondents are male and another $30 \%$ are female. There are 5 respondents' age is 46 above. There are three respondents in the age range of 36 to 45 . The rest of respondents included in "26-35" age group. There are 5 respondents come from College COLGIS. Colleges COB comes from respondent have only one. The rest of respondent included in the CAS college category. 
Section B: Evaluating the Conference Paper Mobile Application (User): In this session, Respondent rated their agreement with question based on Likert scale below.

\begin{tabular}{|c|c|c|c|c|c|c|}
\hline \multicolumn{3}{|c|}{$\leftarrow$ Strongly disagree } & \multicolumn{3}{c|}{ Strongly Agree $\rightarrow$} \\
\hline 1 & 2 & 3 & 4 & 5 & 6 & 7 \\
\hline
\end{tabular}

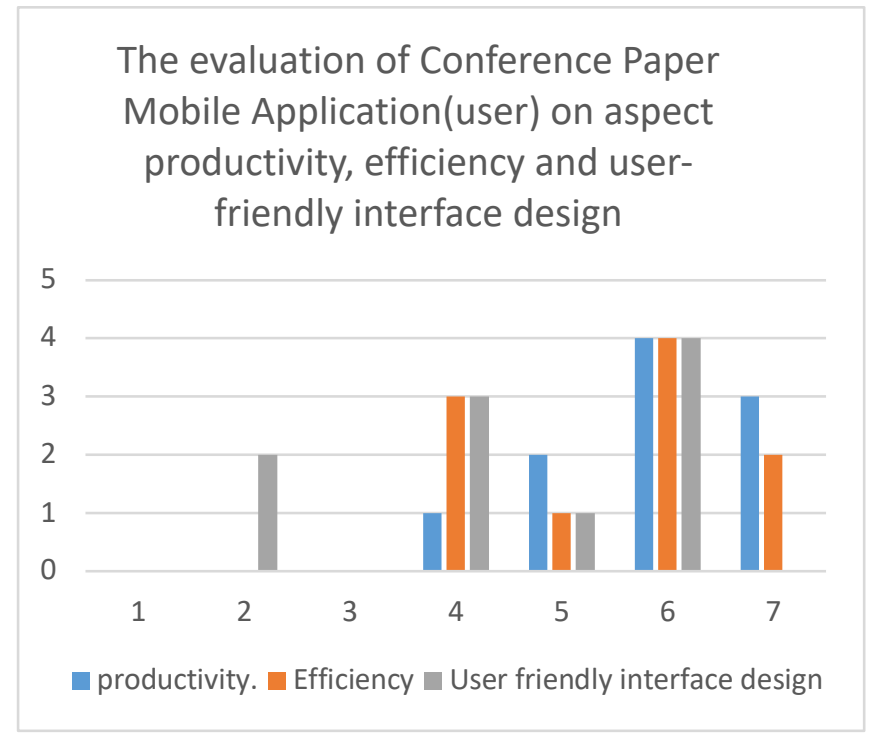

Fig. 6. The evaluation of conference paper mobile application on aspect productivity, efficiency and user-friendly interface design

Ten respondents who are under user group have answered the questionnaire related to aspect productivity, efficiency and user-friendly interface design that have been given to them while undergo this testing study.

Majority respondent has selected positive scale. There are only one respondent choose neutral scale. That means majority respondent agrees that this mobile application can help user to increase productivity in managing conference paper.

In the aspect of efficiency, there are $70 \%$ respondent choose positive scale. The other respondent have chosen neutral scale. That shows most of the respondents think this mobile application is efficient in managing conference papers.

In the aspect of user-friendly interface design, although $50 \%$ respondents have selected positive scale, but $20 \%$ respondent has selected " 2 " scale which is negative scale. This has shown that the interface design still has a lot of room for improvement in order to fulfill the user requirement. 


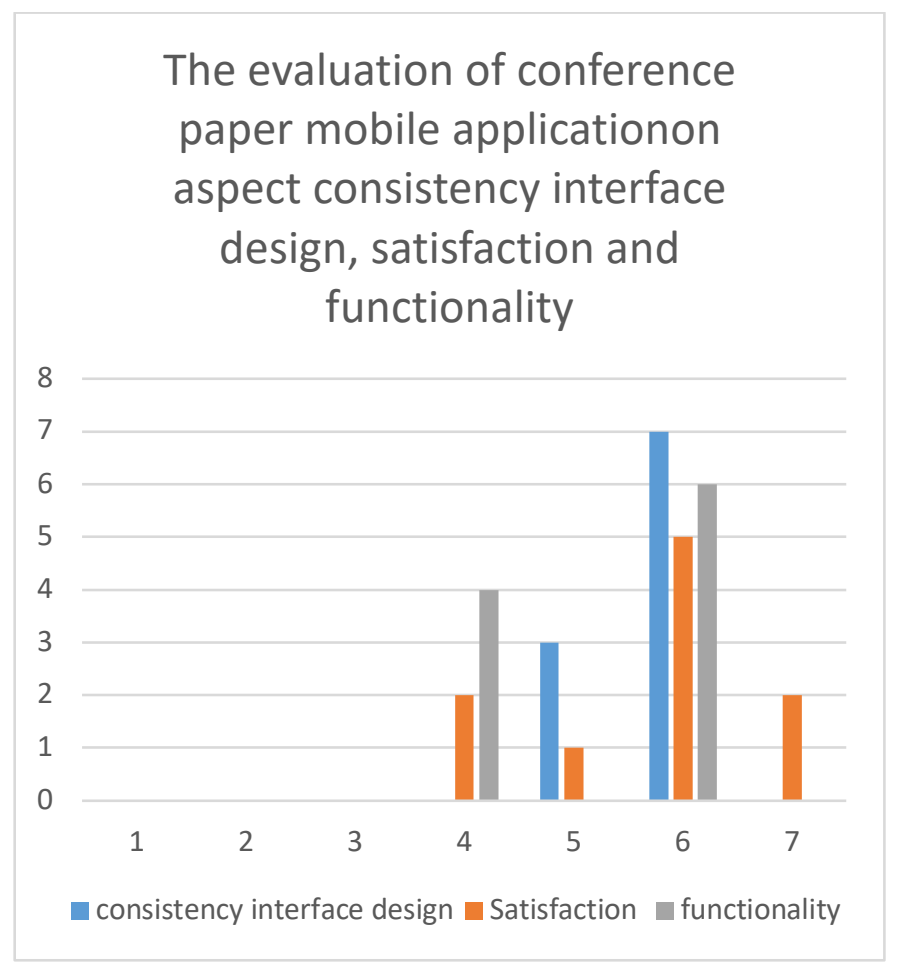

Fig. 7. The evaluation of conference paper mobile application for aspect consistency interface design, satisfaction and functionality.

Ten respondents who are under user group have answered the questionnaire related to aspect consistency interface design, satisfaction and functionality that have been given to them while undergo this testing study.

In the aspect of consistency interface design, there are seven respondents choosing " 6 " scale and the others respondent choose " 5 " scale. In this aspect, all of the respondents have chosen positive scale. Obviously, this has revealed that all respondents agreed that interface design is consistent.

In the aspect of satisfaction, majority respondent has selected positive scale. There are only two respondents choosing a neutral scale. That means majority respondent agrees that the user have satisfied with this mobile application.

In aspect of functionality, $60 \%$ respondent has selected " 6 " scale. The rest of respondent has selected " 4 " scale. The data have revealed that conference paper mobile application is functionality for managing conference paper.

Section A: Demography and background (Admin): Analysis from the admin group questionnaire about the demographic information revealed that the total number of admin group respondents has five respondents. All of them are an academia/staff. $60 \%$ of respondent are male and another $40 \%$ of respondent are female. There are three respondents in the age range of 35 to 45 . Another two respondents are under 
"26-35" age group. There are four respondents come from College CAS. The left one respondent is coming from college COB.

Section B: Evaluating the Conference Paper Mobile Application (Admin): In this session, Respondent rated their agreement with question based on the scale below.

\begin{tabular}{|c|c|c|c|c|c|c|}
\hline \multicolumn{3}{|c|}{$\leftarrow$ Strongly disagree } & & \multicolumn{3}{c|}{ Strongly Agree $\rightarrow$} \\
\hline 1 & 2 & 3 & 4 & 5 & 6 & 7 \\
\hline
\end{tabular}

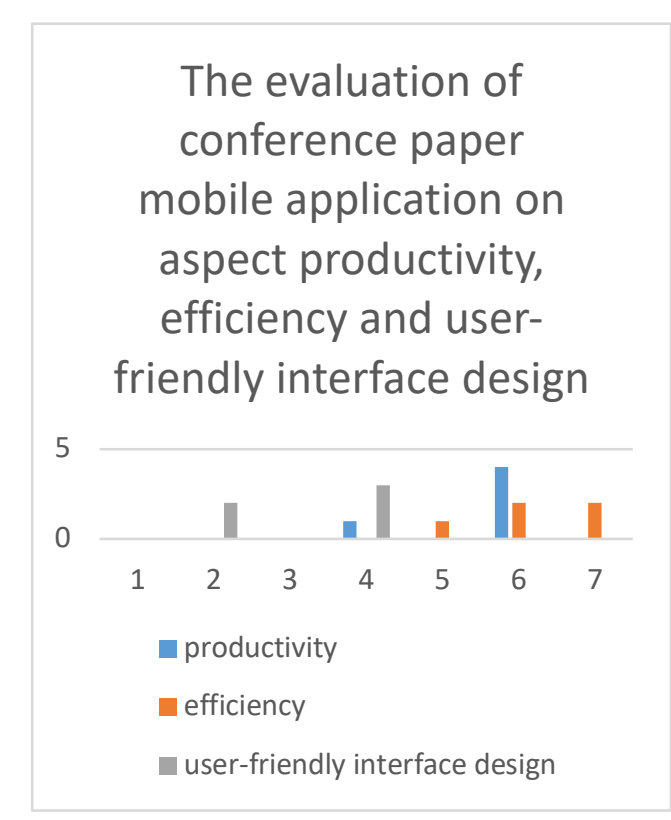

Fig. 8. The evaluation of conference paper mobile application on aspect productivity, efficiency and user-friendly interface design

Five respondents who are under admin group have answered the questionnaire related to aspect of productivity, efficiency and user-friendly interface design that have been given to them while undergo this testing study.

In the aspect of productivity, there are four respondents have selected " 6 " scale and the left one respondent selected " 4 " scale. This show majority respondent agreed that this mobile application can help user to increase productivity in managing conference paper.

In the aspect of efficiency, the entire respondent has selected positive scale. That shows all of the respondents think this mobile application is efficiency in managing conference paper.

In the aspect of user-friendly interface design, there are $60 \%$ respondent have chosen " 4 " scale. Another 40\% respondent has selected "2"scale. Although majority respondent has selected neutral scale, but there two respondents have selected negative. This means there are respondent who are not satisfied with interface design. 
The evaluation of conference

paper mobile application (admin)

on aspect consistency interface, satisfaction and functionality

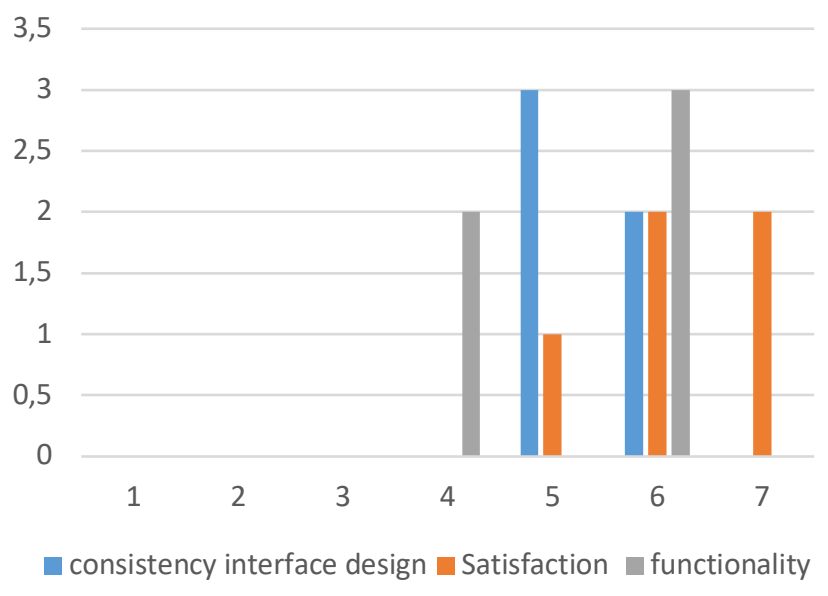

Fig. 9. The evaluation of conference paper mobile application on aspect consistency interface, satisfaction and functionality.

Five respondents who are under admin group have answered the questionnaire related aspect of interface consistency, satisfaction and functionality that have been given to them while undergo this testing study.

In the aspect of consistency interface design, there are seven respondents selected " 6 " scale and the others respondent chosen " 5 " scale. In this aspect, the entire respondent has chosen positive scale. Obviously, these have revealed that all respondents agreed that interface design is consistent.

In the aspect of satisfaction, all respondents have selected positive scale. That means all respondents have agreed that user have satisfied with this mobile application.

In aspect of functionality, $60 \%$ respondent has selected " 6 " scale. The rest of respondent has selected " 4 " scale. The data have revealed that conference paper mobile application is functionality for managing conference paper.

The outcomes of the evaluation suggested that CPMA is useful and easy to use. Further, the respondents reported they were satisfied with the feature of the app like to manage submission, view the submitted conference paper. Besides that, Analysis of the respondents' feedback about the specific features offered by CPMA shows that most of the respondents agree that the registration, login, create submission, and withdraw the submitted conference paper were straightforward and useful. But, some 
of respondents not satisfied with the appearance of the mobile app based on the finding result.

\section{$5 \quad$ Conclusion and Future Works}

This paper describes the design and development of a mobile app for creating and managing conference paper. There are many aspects of grocery lists can be studied. In the future, we plan to expand the functionality of CPMA by providing support towards creating and managing conference paper. Based on analysis of the finding, we found that the appearance of the mobile app is not satisfied by user. In the future, the appearance of the CPMA will be focused on improving user experience. Available to use in only online mode is sometimes troublesome. Development of offline mode allows users to perform some function the application is connection is not available. Once users are connected to connection, only then the application will synchronize with an online database.

\section{References}

[1] A. Mendoza, "Your Desktop Experience Is Not Your Mobile Experience," Mobile User Experience, pp. 11-17, 2014. https://doi.org/10.1016/b978-0-12-409514-4.00003-9

[2] D. M. L. Williams, “"Collaborative mobile user interface design," Proceedings of the 8th conference on Human-computer interaction with mobile devices and services - MobileHCI 06, 2006. https://doi.org/10.1145/1152215.1152271

[3] E.-S. M. El-Rabaie, "Difference between conference paper and research paper," Researchgate, 08-Aug-2018. [Online].Available:

[4] https://www.researchgate.net/post/What_is_the_difference_between_conference_paper_an d_research_paper.

[5] F. Cheng, "Basic App Structure," Build Mobile Apps with Ionic 2 and Firebase, pp. 47-55, 2017. https://doi.org/10.1007/978-1-4842-2737-4_3

[6] Floyd, C. (1984) A Systematic Look at Prototyping, in: Budde, R., Kuhlenkamp, K., Mathiassen, L. and Zullighoven, H. (Eds.) Approaches to Prototyping, Springer-Verlag: Heidelberg, 1-17. https://doi.org/10.1007/978-3-642-69796-8

[7] J. A. T. d. Silva, "On the Abuse of Online Submission System, Fake Peer Reviews and Editor-Created Accounts," vol. 20, no. 2, p. 153, 2016.

[8] M. Rashedul, M. Rofiqul, and T. A. Mazumder, "Mobile Application and Its Global Impact," International Journal of Engineering \& Technology, vol. 10, no. 06, pp. 106-107.

[9] M.Ware, "Online Submission and Peer Review System Available," Archives of Ophthalmology, vol. 123, no. 2, p. 165, 2005.

[10] P. Bridge and R. Appleyard, "A comparison of electronic and paper-based assignment submission and feedback," British Journal of Educational Technology, vol. 39, no. 4, pp. 644-650, 2008. https://doi.org/10.1111/j.1467-8535.2007.00753.x

[11] S.-H. Lee, "Mobile Phone Culture: The Impacts of Mobile Phone Use," Encyclopedia of Mobile Phone Behavior, pp. 658-672.J. Clerk Maxwell, A Treatise on Electricity and Magnetism, 3rd ed., vol. 2. Oxford: Clarendon, 1892, pp.68-73. https://doi.org/10.4018/ $\underline{978-1-4666-8239-9 \cdot \operatorname{ch} 055}$ 
[12] T.Padmapriya, S.V. Manikanthan, "LTE-A Intensified Voice Service Coder using TCP for Efficient Coding Speech", International Journal of Innovative Technology and Exploring Engineering, Vol. 8, issue 7s, 2019.

[13] Y.Zheng, "Mobile Phone Behavior in Daily Life," Mobile Phone Behavior, pp. 242-269. https://doi.org/10.1017/9781316417584.010

\section{$7 \quad$ Authors}

Azham Hussain is the Associate Professor of Software Engineering at School of Computing, Universiti Utara Malaysia, Kedah, Malaysia. He is the founder of Human-Centered Computing Research Group, which is affiliated with the Software Technology Research Platform Center at School of Computing, Universiti Utara Malaysia. Azham Hussain is a member of the US-based Institute of Electrical and Electronic Engineers (IEEE), and actively involved in both IEEE Communications and IEEE Computer societies.

Chow Chun Leong is a student at School of Computing, Universiti Utara Malaysia, Kedah, Malaysia. His research interest includes web development, mobile application development and machine learning. azhamuum@gmail.com

Nurnasran Puteh is a Lecturer at School of Computing, Universiti Utara Malaysia, Kedah, Malaysia. His research interest is in the domain of Distributed System specifically in the fields of web services, semantic web-based system and open linked data. The current research focus is in the application of semantic web in the Islamic domain, such as the integration of semantic search in the building Mosque portal. Current research also includes the application of linked data technology such as RDF, SPARQL and JSON LD in linking Islamic related data such as AlQuran and Hadith. nasran@uum.edu.my

Zarul Fitri Zaaba, Ph.D, is a Senior Lecturer at the School of Computer Sciences, Universiti Sains Malaysia. He obtained his M.Sc Information Security from the Royal Holloway University of London and Ph.D from the University of Plymouth, United Kingdom. Prior to joining USM, he had worked for few years with government and semi-government sector. He specializes in information security with current areas of interest, including security, usability, security management, privacy, usable security and the human aspects of security. His new interest is on the computational thinking (CT) in Science, Technology, Engineering, Mathematics (STEM). He can be contacted via zarulfitri@usm.my

Article submitted 2019-07-14. Resubmitted 2019-08-09. Final acceptance 2019-08-11. Final version published as submitted by the authors. 